\title{
Prevalence of Anxiety, Difficulties and Quality of Life of Patients with Chronic Renal Disease at Pediatric Service at University Hospital Center "Mother Theresa"
}

\author{
Jeta Ajasllari \\ Phd. Candidate, Department of Psychology and Pedagogy, Faculty of Social Science, Albania. \\ Email: j.ajasllari@live.com
}

\section{Doi:10.5901/ajis.2015.v4n2s2p145}

\section{Abstract}

\begin{abstract}
Chronic kidney disease (CKD), is an illness that causes grave and irreversible reduction of kidney function, affecting the physical, social and emotional wellbeing of the child. Although over the last years medical care and management of children with chronic kidney disease (CKD) has been effective and there have been changes in the prognoses of these patients, the implications on their health and well being remain deep ones. The aim of this study was to assess the prevalence of anxiety, difficulties and quality of life (QoL) as risk factors in children diagnosed with CKD, an assesment which will affect the prognoses and clinical follow-up of these patients. 30 patients of age of 11-15 years diagniosed at Mother Theresa University Hospital Cenetr were included in the study. In these study, were used three instruments: State-Trait Anxiety Inventory (STAI), (PedsQI) Pediatric Quality of Life Inventory and Strengths and Difficulties Questionnaire (SDQ). Based on the analyses of data it resulted that $97 \%$ of the patients were suffering with high level of difficulty. As regards the level of anxiety more than half of the patients (60\%) reported high levels and $40 \%$ of them anxiety of average level. The analyses of quality of life revealed that $53 \%$ had low quality of life, the other part (47\%) an average level. The medical problems of these patients are accompanied with psychological complications. Comprehension of their experience is important for the planning and provision of the respective services, as well as the reduction of the impact of the illness. In this context, this study is an initiator for other researches which should be qualitative, such researches focused on the patient will help to understand the perceptions of this patients with CKD, how they experience their disease.
\end{abstract}

Keywords: CKD, QoL, anxiety, difficulty, chronic disease

\section{Introduction}

Chronic kidney disease is a major public health problem. Chronic kidney disease (CKD), also known as chronic renal disease, is a progressive loss in renal function over a period of months or years. Based on the criteria proposed by National Kidney Foundation (2002), CKD is classified into 5 stages based on the problem and functioning of patient's kidneys. In the most advanced stages 4, 5 End Stage Renal Disease (ESRD), at which the kidneys no longer can sustain the body homeostasis, the patient is dependant on one of the modalities of replacement therapy (renal replacement therapy (RRT): undergoes the process of dialysis or kidney transplant. Conservative management refers to treatment without having dialysis or a transplant. The aim of conservative management is to maintain a good quality of life by prolonging kidney function and controlling symptoms

Medical progress such as dialysis and kidney transplant have obviosly increased the chances of survival for children and adolescents with CKD. However, non-fuction of an organ is corrected only partially, leaving great consequences on general health and quality of life of patients (Roventa et al. 2011). Co-existace of children for a long time with such a problem as renal disease is very difficult and affects their life in various ways. Parallelly, CKD causes grave psychological damages, which are even graver in those patients who are at the last stages and need renal replacement therapy (RRT, Dialysis).

Systematic psychological research on adaption of children to CKD-se started in year 1970 (Korsch et al. 1973), but interest of psychology on health and disease seriosly commenced about 30 years ago (Terborg, 1985) and ever more aims at understanding of illness experiences. However there have been few studies which have adressed the case of clinical and social factors which damage HRQOL (Goldstein \& Gerson, 2007).

Psychological literature often claims that children with chronic renal disease "were found in increasing danger for psychological lack of adaption compared to their healthy peers" (Madden et al. 2002). Children with CKD are often reported to face difficulty with their psycho-social adaption (Marland, 1995). It also presents a social cost especially as result of treatment regimens which limit the "activity" of these children an socialising (Snethen et al. 2001). Researchers 
over the years have noticed difficulty in education of children and adolescents with CKD (Lawroy et al.,1994).

It has been observed that they present a higher risk of worse psychosocial performance than their healthy peers (Holden et al. 1997). According to a study of Madden et al. (2003) which explored the cognitive and psycho-social results of children receiving dialysis since little age, it resulted that more than half of participants demonstrated behaviour and emotional problems. Everyday life of these children changes due to some limitations, mainly physical ones, because of the characteristics of the disease which require constant re-adaption as well as development of strategies to face the desease. They undergo diet and hidric limitations, difficult invasive treatments and hospitalization. Quality of life (QoL) of patients with CKD is damaged considerably because of requirements as consequence of conditions and their clinical treatment (Soliday, Kool \& Lande, 2001). They experience a wide range of somatic symptoms, anxiety and decrease of quality of life (Murtagh et al. 2007).

Although anxiety, which accompanies CKD, may have negative effects on functioning and physical health, so far there are no satisfactory data on QOL which reveal that psychological treatment of anxiety and difficulties of patients with CKD improves the clinical symptoms and quality of life (Reuben \& Tinetti, 2012). Concern to promote quality of health care has developed together with the model of humanization of medicine which cares for patient satisfaction, suggesting special management choices which may have been adapted according to the needs of patients and personal choices (Varni, 2004).

Addressing of preferences and needs of the patient in order to improve health care is accepted as a very important component to offer a better health care, especially to patients with chronic disease (Tong et al. 2008).

Although treatment remains quite invasive, it requires deep changes in behavior and lifestyle.

Some studies which use simple interventions, showed that stimulation of these children to carry out activities that are normal for their peers may be useful (Balen, Fielding \& Lewis, 1996).

\section{Research Methodology}

In the study were included (30) patients of age (11-15 years old) diagnosed with chronic renal diesease (CKD) who respectively followed hemodialysis $(H D, n=3)$, peritoneal dialysis $(P D, n=1)$ and conservative therapy $(C T, n=26)$, patients who were receiving treatment at Pediatric Service of "Mother Theresa" University Hospital Center at Nephrology/Dialysis service. The criteria of participation in the study were: participants wuold be patients of age 11- 15 years old diagnosed with chronic renal disease (CKD) stage 4-5 and those under process of Dialysis (Hemodialysis, Peritoneal Dialysis). Personal clinical data of the patients were received through a questionaire atatched to the instruments, which contained data such as: age, gender, diagnoses, diagnosing age, disease stage. From the participants and parents was requested initial consent for participation in the study and also they were informed in advance on the importance of the completion of instruments. They were made aware that they completion would be useful to follow the changes in the progress of the disease of the child in the best possible way. Information in this questionaire would be kept strictly confidential and would be used only for clinical and research activity. All data would be used anonymously. State Anxiety Scale (Spielberge). The State Anxiety Inventory (STAI) is a psychological inventory based on a 4-point Likert scale and consists of 20 questions on a self-report basis. The STAI measures higher scores are positively correlated with higher levels of anxiety. STAI is one of the mostly used scale worldwide. Pediatric Quality of Life Inventory (PedsQL) Pediatric Quality of Life Inventory (PedsQL) is a scale created to measure HQOL of children and adolescents 2 to 18 years old. In order to measure the impact of illness or medical treatment on patients. PedsQL provide us with information related to physical functioning, emotional functioning, social functioning, school functioning. PedsQL scale contains 32 items. Researchers, policy-makers, providers, and health plans will find the PedsQL a welcomed addition to pediatric health outcomes evaluation. Strengths and Difficulties Questionnaire (SDQ): The Strengths and Difficulty Questionnaire (SDQ) is a brief child mental health questionnaire for children and adolescents ages 2 through 17 years old, developed by the UK child psychiatrist Robert N. Goodman (1997). The instrument contains 25 items, which includes emotional symptoms, conduct problems, hyperactivity/inattention, peer relationship problems, prosocial behaviour. Initially it was taken the consent of parents for aprticipation in the research study and later it was proceeded with the application of the instruments.

\section{Analyses and Findings}

The aim of this study was to asses prevalence of anxiety, difficulties and quality of life (QoL) as risk factors in children diagnosed with chronic renal disease (CKD) the evaluation of which will impact the progoses and clinical conditiones of 
these patients.

Table. Information on gender of participants, age, diagnoses, period of diagnosing and disease stage

\begin{tabular}{|c|c|}
\hline $\begin{array}{l}\text { Gender of participants } \\
\text { Male - } 22 \text { patients }(73 \%) \\
\text { Female - } 8 \text { patients }(27 \%)\end{array}$ & $\begin{array}{l}\text { Diagnoses and stage of disease } \\
\text { Nephrotic Syndrome /Stage } 4-17 \text { patients (57 \%) } \\
\text { Chronic Renal Insufficiency / Stage } 5 \text { - } \\
13 \text { patients (43 \%) }\end{array}$ \\
\hline $\begin{array}{l}\text { Diagnosing Period } \\
\text { The time span over which the participants lived with this illness } \\
\text { was from } 2 \text { to } 13 \text { years from the diagnosing period. } \\
2-5 \text { year diagnosed - } 16 \text { patients ( } 53 \% \text { ) } \\
6-9 \text { years diagnosed - } 9 \text { patients ( } 30 \%) \\
10-13 \text { years diagnosed - } 5 \text { patients ( } 17 \%)\end{array}$ & $\begin{array}{l}\text { Dialysis } \\
\text { Patients ion the last stage (5) of the disease undergo the } \\
\text { dialysis process. } \\
\text { Peritoneal Dialysis }-1 \text { patient }(3 \%) \\
\text { Hemodialysis - } 3 \text { patients }(10 \%) \\
\text { No Dialysis - } 26 \text { patients }(87 \%)\end{array}$ \\
\hline
\end{tabular}

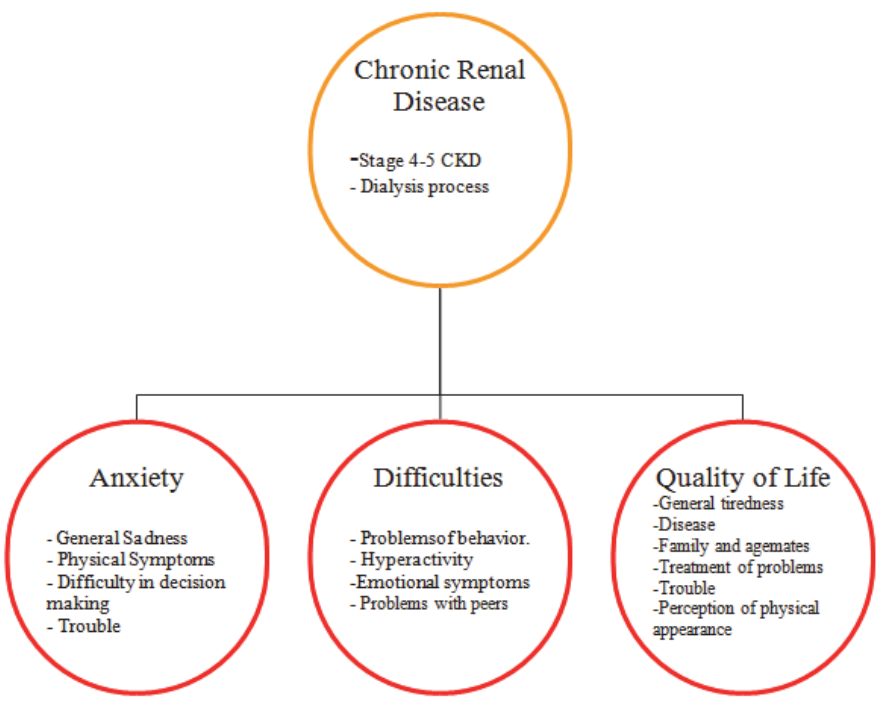

Scheme. Study Structure

Results are presented as follows:

\subsection{Data on anxiety (STAIC)}

Out of 30 participants asked on the level of anxiety experienced by them, experienced:

High Anxiety - 18 patients (60\%)

Moderate Anxiety - 12 patients ( $40 \%)$

Low Anxiety - 0 patients (0\%)

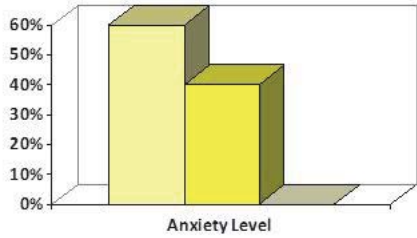




\subsection{Data on Difficulties. (SDQ)}

Out of 30 participants asked on the level of difficulty experienced by them, experienced:

High Level of Difficulty - 29 patients ( $97 \%$ )

Moderate level of Difficulty - 0 patients ( $0 \%)$

Difficulty of low level - 1 patient (3\%)
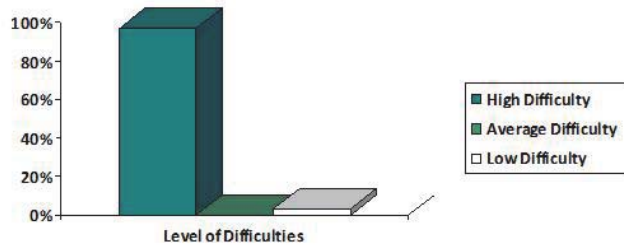

Chart 2 .Levels of Difficulty

Out of 30 participants asked on the level of anxiety experienced by them, experienced:

High Quality of Life - 0 patients (0\%)

Moderate Quality of Life - 14 patients (47\%)

Low Quality of Life - 16 patients ( 53\% )

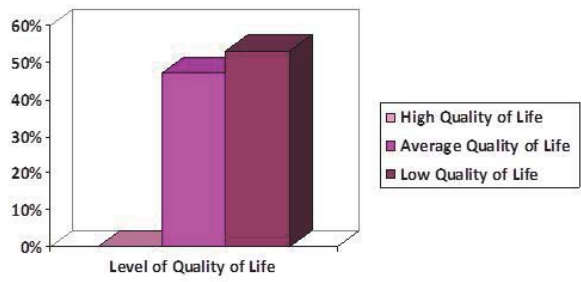

Chart 3. Levels of Quality of Life.

Based on the results we notice that patients diagnosed with chronic renal disease experience high levels of anxiety, difficulties and their quality of life is very low. Analysing the data we see that $97 \%$ of the patients have high level of difficulty. Practically only 1 (one) participant reports low level of difficulty, the rest of the participants experience great difficulties. As regards the level of anxiety more than half of them reports high levels of anxiety, the rest report anxiety of moderate level, no participants were lacking anxiety. As regards quality of life it is noticed that patients with chronic renal disease (CKD) have quality of life related to their health in very low level (53 \%), the rest have an average level of quality of life (47\%). Analyses of the data also reveals that patients who have lived with the disease for a longer period of time have a tendency to experience more difficulty, experience high levels of anxiety and their quality of life related to health is very low. Patients with short period of diagnosing from 2 to 4 years experienced high difficulty in life their aspects but in general had anxiety of moderate level, and quality of life related to health of an moderate level. Disease stage is another very important factor.

Patients undergoing Hemodialysis and Peritoneal Dialysis process, who had a long period of co-existance with this chronic diagnosis and fight with renal disease, were all experiencing high levels of anxiety, difficulty and low quality fo life. Medical problems of these patients are accompanied with psychological complications and the individual factors. Qulity of life (QoL) of patients with CKD is damaged in a considerable way because of the requests as consequence of their condition and clinical treatment. (Soliday, Kool \& Lande, 2001). They experience a wide range of somatic symptoms, anxiety and decrease of quality of life. (Murtagh, Addington-Hall, Edmonds et al. 2007).

Based on the delicate age of children and the limitations caused by the illness itself, the impact of the disease is high and complications increase more and more. Limitations to food, diet in liquids, limitation of physical activity, burdened emotional state do not seem easy to deal with those patients. 


\section{Conclusions}

Findings reveal a weak adaption of patients with chronic renal disease at the last stages 4-5. Children and adolescents with chronic renal disease who undergo invasive procedures do not have a good growth experience, they have problems at school and social problems. They have high anxiety, difficulty and low quality of life related to their health which affects their self-esteem, self-control, the perception they have on themselves and relations with other peers and their family members.

Understanding the esperience of patients is important to offer effective health, to plan and provide the respective services, as well as to reduce the impact of chronic renal disease on children and adolescents by assisting them to improve their behaviour, mood and increase their quality of life. Treatment of patients with chronic renal disease requires multy-disciplinary care, medical and psychological. A very important role is also played by their family members as an essential point for their adaption with the chronic disease. Interventions are important to assit the child to manage his/her health, to get involved in the community to actively participate in different creative activities, to be asssited to progress in lessons and be on the alert towards medical treatments. In this context, this study is an initiator for other researches which should be qualitative, such researches focused on the patient will help us to understand the perceptions of this patients with CKD, how they experience their disease.

\section{References}

Balen R, Fielding D, Lewis I. (1996). Activity Camps for Children with Cancer. Children and Society; 10:317-23.

C.E. Roventa, C. Poenar, A. Niculae and G. Lupusoru, Practica Medicala. (2011). 1(21) 7.

Goldstein SL, Gerson AC. (2007). Health-related quality of life for children with chronic kidney

Disease. Adv Chronic Kidney Dis.

Goldstein, S.L., Graham, N., Warady, B.A., Seikaly, M., McDonald, R., Burwinkle, T.M., Limbers, C.A., \& Varni, J.W. (2008). Measuring health-related quality of life in children with ESRD: Performance of the Generic and ESRD-Specific Instrument of the Pediatric Quality of Life Inventory ${ }^{\mathrm{TM}}$ (PedsQL ${ }^{\mathrm{TM}}$ ). American Journal of Kidney Diseases, 51, 285-297.

Goodman, R.(1997) The Strengths and Difficulties Questionnaire: a research note. J Child Psychol Psychiatry,. 38(5): p. 581-6

Holden W, Chmielewski D, Nelson CC, Kager VA, Foltz L. (1997). Controlling for general and disease-specific effects in child and family adjustment to chronic childhood illness. J Pediatr Psychol; 22:15-27.

Korsch B, Negrete V, Gardner J, Weinstock C,Mercer A, Grushkin C \& Fine R. (1973). Kidney transplantation in children: psychosocial follow-up study on child and family. The Journal of Pediatrics 83,399-408.

Lawry K, Brouhard B \& Cunningham R. (1994). Cognitive functioning and school performance in children with renal failure. Pediatric Nephrology 8, 326-329.

Madden S, Hastings R \& Hoff. (2002). Psychological adjustment in children with end stage renal disease: the impact of maternal stress and coping. Child Care, Health \& Development 28, 323-330.

Madden SJ, Ledermann SE, Guerrero-Blanco M \& Bruce M. (2003). Cognitive and psychosocial outcome of infants dialysed in infancy.Child Care, Health and Development.

Marland, S. (1995). 25th annual conference of the European working group on psychosocial aspects of children with chronic renal failure.Pediatric Nephrology 9, 123.

Murtagh FE, Addington-Hall JM, Edmonds PM et al. (2007). Symptoms in advanced renal disease: a cross-sectional survey of symptom prevalence in stage 5 chronic kidney disease managed without dialysis. J Palliat Med ; 10: 1266-1276.

National Kidney Foundation (2002). "K/DOQI clinical practice guidelines for chronic kidney disease" Retrieved 2008-06-29.

Reuben DB, Tinetti ME. (2012). Goal-oriented patient care--an alternative health outcomes paradigm. N Engl J Med ; 366: 777-779.

Snethen JA, Broome ME, Bartels J\&Warady BA. (2001). Adolescents' perception of living with end stage renal disease. Pediatric Nursing27, 159-161.

Soliday E, Kool E, Lande MB. (2001). Family environment, child behavior, and medical indicators in children with kidney disease. Child Psychiatry Hum Dev; 31:279-95.

Spielberger, C.D., Sydeman, S.J. (1994). State-Trait Anxiety Inventory and State-Trait Anger Expression Inventory. In M.E. Maruish (Ed.), The use of psychological testing for treatment planning and outcome assessment. (pp. 292-321). Hillsdale, NJ: Lawrence Erlbaum Associates.

Terborg, JR. (1998). Health psychology in the United States: a critique and selective review. Applied Psychology: An International Review 47, 199-217.

Tong A, Sainsbury P, Carter SM et al. (2008). Patients' priorities for health research: focus group study of patients with chronic kidney disease. Nephro Dial Transplant ; 23: 3206-3214.

Varni, JW. (2004). Health-related quality of life measurement in pediatric clinical practice. 